\title{
Spectrum of seizure disorder in children between 1-18 yrs age at a tertiary care hospital: a longitudinal study
}

\author{
Dua H. ${ }^{1}$, Edbor A. ${ }^{2 *}$, Kamal S. $^{3}$
}

DOI: https://doi.org/10.17511/ijpr.2020.i01.01

\footnotetext{
1 Himanshu Dua, Associate Professor, Department of Paediatrics, NKP Salve Institute of Medical Sciences, Nagpur, Maharashtra, India.

${ }^{2 *}$ Anjali Edbor, Associate Professor, Department of Paediatrics, NKP Salve Institute of Medical Sciences, Nagpur, Maharashtra, India.

${ }^{3}$ Seher Kamal, Jr. Resident, Department of Paediatrics, NKP Salve Institute of Medical Sciences, Nagpur, Maharashtra, India.
}

Background: To study the spectrum of seizures and types of anti-epileptic drugs in various types of seizures in children. Methods: A hospital based longitudinal study was conducted in the department of Pediatrics over two-years of period. A total of 161 cases presenting with seizures were studied for clinical features, imaging studies, EEG and pharmacotherapy given for various types of seizures (Monotherapy / combination therapy). Results: In the present study, the patient's age ranged from 1 year to 18 years. There were $72(44.7 \%)$ females and $89(55.2 \%)$ males. The male to female ratio was 0.8. Investigation like EEG, neuroimaging which included MRI / CT SCAN BRAIN were done. Out of 161 cases, EEG was done in all the cases, 89.44\% (144) had EEG abnormality. 11\% (17) presented with no EEG abnormality and MRI was done in $80.21 \%$ (129), out of which $53.48 \%$ (68) were abnormal, CT scan was done in $19.87 \%$ (32) of which $21.87 \%$ (7) were abnormal. Maximum used pharmacotherapeutic agent was sodium valproate $(46.3 \%)$ for generalised tonic clonic (GTCS) and minimum was combination of 3 anti-epileptic drugs (7\%). Conclusion: Seizures in children are a common indication for hospital admission. They can be provoked or unprovoked. Early detection of the cause of seizures helps in instituting appropriate treatment. Children with seizures should be on regular long term follow up and treatment and proper response to therapy should be evaluated. Evaluation of the type of seizure with specific EEG findings helps in early and appropriate initiation of AED.

Keywords: Seizure disorder, Epilepsy, Electroencephalogram (EEG), Computed tomography (CT), Magnetic resonance Imaging (MRI)

Corresponding Author

Anjali Edbor, Associate Professor, Department of Paediatrics, NKP Salve Institute of Medical Sciences, Nagpur, Maharashtra, India.

Email: dranjaliedbor@gmail.com

\section{How to Cite this Article}

To Browse

Dua H, Edbor A, Kamal S. Spectrum of seizure disorder in children between 1-18 yrs age at a tertiary care hospital: a longitudinal study. Pediatric Rev Int J Pediatr Res. 2020;7(1):1-7.

Available From

https://pediatrics.medresearch.in/index.php/ijpr/arti cle/view/565

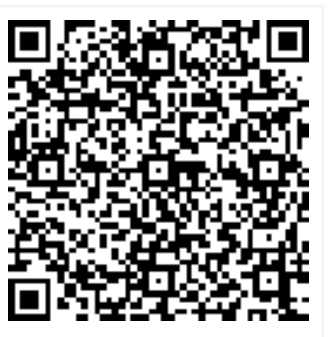

Manuscript Received 2019-11-26

Conflict of Interest No (c) 2020 by Himanshu Dua, Anjali Edbor, Seher Kamal and Published by Siddharth Health Research and Social Welfare Society
This is an Open Access article licensed under a Creative Commons Attribution 4.0 International License https://creativecommons.org/licenses/by/4.0/ unported [CC BY 4.0].

Review Round 2 2019-12-14

Review Round 1 2019-12-06

Funding

(1)
Accepted 2019-12-18

Note 


\section{Introduction}

Seizure represents the clinical expression of abnormal, excessive, synchronous discharges of neurons residing primarily in the cerebral cortex. This abnormal paroxysmal activity is intermittent and usually self-limited, lasting seconds to a few minutes.

Epilepsy is not a specific disease, but rather a condition arising from a variety of pathological insults involving the cortex, such as tumors or genetic channelopathies etc. Serial seizures caused by hypoglycemia, hyponatremia, hypocalcemia, febrile seizures, meningitis, head trauma are not classified as epilepsy unless they become a recurrent process beyond the acute illness.

International League Against Epilepsy (ILAE) defines epilepsy as "Epilepsy is a disorder of the brain characterized by an enduring predisposition to generate epileptic seizures and by the neurobiological, cognitive, psychological, and social consequences of this condition" [1]. Epilepsy is a common medical illness worldwide.

It is estimated that $0.5-1 \%$ of all children have epilepsy, with the majority presenting during infancy or early childhood [2]. The incidence is highest from 12 months of life through 2 years of age which is due to epilepsy associated with mental retardation and cerebral palsy [3]. Also epilepsy increases the mortality. But it is known that childhood epilepsy has a better prognosis when compared to epilepsy in adults [4].

The prevalence rate (PR) of epilepsy for developed and developing countries has a wide range and has been reported between $3 / 1000$ and 22.2/1000 [57]. The high incidence in developing countries is attributable to high incidence of parasitosis like neurocysticercosis (NCC), central nervous system (CNS) infections, HIV, head injury and perinatal morbidity [8].

The incidence of epilepsy (recurrent unprovoked seizures) in children and adolescents seems relatively consistent across all populations studied, ranging from 50 to100/100, 000 person-years [9].

However, seizure may be the initial presentation of serious medical condition like meningitis / cerebral malaria. Early identification of etiology with clinical correlation and early initiation of treatment is imperative for better outcome.

\section{Objectives}

01 . The primary objective of this study is to know the spectrum of seizures in children between 1 18 years age.

02. To observe the AED used for different types of seizures.

03. To correlate EEG abnormality with neuroimaging (MRI brain/ CT scan brain) done.

\section{Materials and Methods}

Study design: A hospital based longitudinal study.

Setting: Department of Pediatrics at a tertiary care hospital catering to health care needs of lower and middle class income group patients.

Duration of study: 2 years (from June 2017 to June 2019)

Sample size: 161 cases that presented with complaints of seizures and were admitted in the pediatric ward. This sample size was calculated as per formula given by Basagana et al [10].

\section{Inclusion criteria}

Age group of 1 to 18 years

First unprovoked seizures

Recurrent episodes of seizures

Parents/patients willing to give consent for inclusion in the study.

\section{Exclusion criteria}

- Febrile seizures

- Parents/patients not willing to give consent for inclusion in the study.

Data Collection Procedure: Clinical history was taken including patients age and gender, type of seizure, associated symptoms (fever, cough, rhinorrhea, vomiting, diarrhea and headache), family history of seizure or epilepsy and consanguinity, birth history, developmental history, immunization status, past history of seizures and treatment history. Routine laboratory investigations were done including complete blood picture, (hemogram), CSF study, (if indicated), complete urine examination, serum C-reactive protein, serum electrolytes, blood glucose estimation as per protocol for seizure. Appropriate investigation in the form of EEG, CT scan and/or MRI was done according to etiology and findings were tabulated. 
01. Data analysis: All the data was analyzed by descriptive statistics and expressed in terms of percentage. The analysis was done in Microsoft Excel 2013.

02. Ethics approval: The study was approved by the institutional ethics committee of the. A written consent was taken from all of the participants after explaining the details, benefits, and risks to them.

Operational Definitions: A seizure is defined as "a transient occurrence of signs and/or symptoms due to abnormal excessive or synchronous neuronal activity in the brain. The term transient is used as demarcated in time, with a clear start and finish."

Classically Status Epilepticus was defined as "a condition characterized by an epileptic seizure that is sufficiently prolonged or repeated at sufficiently brief intervals so as to produce an unvarying and enduring epileptic condition."

Generalized convulsive SE in adults and children older than 5 years was operationally defined as $\geq 5$ min of (1) continuous seizure or (2) two or more discrete seizures between which there is incomplete recovery of consciousness."

\section{Results}

Total number of cases admitted in pediatric ward who presented with seizures was 161 . Out of these, $89(55.2 \%)$ patients were male, and $72(44.7 \%)$ were female. The male to female ratio was 0.8. 105 patients $(65 \%)$ were born through term delivery, 53 $(33 \%)$ pre term, and 3 patients $(2 \%)$ with post term delivery. In the present study, the patient age ranged from 1 year to 18 years (Table 1 ).

Table-1: Gender wise distribution and the type of delivery.

\begin{tabular}{|l|l|l|}
\hline \multicolumn{1}{|c|}{ Demographics } & \multicolumn{1}{|c|}{ Frequency/ Count } & Percentage \\
\hline Gender & 89 & $55.2 \%$ \\
\hline Male & 72 & $44.7 \%$ \\
\hline Female & \multicolumn{2}{|l|}{} \\
\hline Type of delivery & $65 \%$ \\
\hline Term delivery & 105 & $33 \%$ \\
\hline Preterm & 53 & $2 \%$ \\
\hline Post term & 3 & \\
\hline
\end{tabular}

Table 2: Distribution of gender in different age groups.

\begin{tabular}{|l|l|l|}
\hline \multicolumn{1}{|c|}{ Age } & \multicolumn{1}{c|}{ Male } & \multicolumn{1}{c|}{ Female } \\
\hline $1-5$ years & $22(25 \%)$ & $19(26 \%)$ \\
\hline $5.1-10$ years & $32(36 \%)$ & $26(36 \%)$ \\
\hline
\end{tabular}

\begin{tabular}{|l|l|l|}
\hline $10.1-15$ years & $23(26 \%)$ & $18(25 \%)$ \\
\hline$>15$ years & $12(13 \%)$ & $9(13 \%)$ \\
\hline
\end{tabular}

Majority of the males were in the age group 5.1 to 10 years comprising of 32 patients (36\%), followed by 23 patients $(26 \%)$ in the age group 10.1 to 15 years. Female patients were majority in the age group $5.1-10$ years (46\%), followed by $26 \%$ in the age group of 1 to 5 years (Table 2 ).

Out of total 161 patients on whom electroencephalogram (EEG) was done, it was found that 141 patients (89.4\%) had abnormal EEG, while 17 patients had normal EEG. Magnetic resonance imaging (MRI) was done in 129 patients, out of which 68 patients (53\%) had normal MRI and 61 patients had (47\%) had abnormal MRI. CT scan was done in 32 patients, of which 25 patients (78\%) had normal CT scan, while 7 patients (22\%) had abnormal CT scan (Table 3).

Table-3: Distribution of EEG and Neuroimaging (CT scan/MRI Brain).

\begin{tabular}{|l|l|l|l|}
\hline \multicolumn{1}{|c|}{ Investigation done } & No. of cases & \multicolumn{1}{c|}{ Normal } & Abnormal \\
\hline Electro Encephalogram & 161 & $17(11 \%)$ & $141(89.4 \%)$ \\
\hline Magnetic Resonance Imaging & 129 & $68(53.1 \%)$ & $61(46.87 \%)$ \\
\hline Computed Tomography & 32 & $25(78.1 \%)$ & $7(21.8 \%)$ \\
\hline
\end{tabular}

Out of 161 patients - 98 (60.86\%) patients presented with GTCS, $45(27.95 \%)$ with CPS, 3 $(1.86 \%)$ with partial seizure, 6 (3.72\%) with myoclonic seizures and $9(5.59 \%)$ with mixed seizures (Table 4).

Table-4: Distribution of the participants according to type of seizure.

\begin{tabular}{|l|l|l|}
\hline \multicolumn{1}{|c|}{ Type of seizure } & Frequency & \multicolumn{1}{c|}{$\%$} \\
\hline Generalized tonic clonic seizure & 98 & $60.8 \%$ \\
\hline Complex partial seizure & 45 & $27.9 \%$ \\
\hline Simple Partial Seizure & 3 & $1.8 \%$ \\
\hline Myoclonic Seizure & 6 & $3.7 \%$ \\
\hline Mixed Seizure & 9 & $5.5 \%$ \\
\hline
\end{tabular}

Table-5: Anti-epileptic medication used for different types of seizure.

\begin{tabular}{|l|l|l|l|l|l|}
\hline $\begin{array}{c}\text { Drugs/ Type of } \\
\text { Seizure }\end{array}$ & \multicolumn{1}{|c|}{ GTCS } & \multicolumn{1}{|c|}{ CPS } & Partial & $\begin{array}{l}\text { Myocloni } \\
\mathrm{c}\end{array}$ & Mixed \\
\hline Valproate & $73(97.33 \%$ & $1(1.33 \%)$ & 0 & $1(1.33 \%)$ & 0 \\
\hline Carbamazepine & $3(7.14 \%)$ & $36(85.71 \%$ & $3(7.14 \%$ & 0 & 0 \\
\hline Levetiracetam & $8(61.53 \%)$ & $2(15.38 \%)$ & 0 & $2(15.38 \%$ & 1 \\
\hline CBZ + clobazam & 9 & 4 & 0 & 2 & 1 \\
\hline VALP + clobazam & 4 & 2 & 0 & 1 & 1 \\
\hline Combination of 3 drugs & 1 & 0 & 0 & 0 & 6 \\
\hline
\end{tabular}


In generalized tonic clonic seizures sodium valproate was most commonly prescribed drug comprising of 73 patients (97\%). Carbamazepine was most commonly prescribed antiepileptic drug in complex partial seizures comprising of 36 patients (86\%). In simple partial seizures carbamazepine was most commonly prescribed drug. In myoclonic seizures, levetiracetam was prescribed in 2 patients and valproate was prescribed in 1 patient (Table 5 ).

\section{Discussion}

Epilepsy is significantly common in pediatric age group. It may be associated with other diseases like cerebral malaria, meningitis, etc. The prevalence rises in developing countries. It also increases the morbidity and mortality. Thus, it becomes imperative to catch the disease early and intervene accordingly to optimally control the disease activity. Thus, the present study was planned to analyze the spectrum of epilepsy in pediatric age group.

In the present study, 89 (55.2\%) patients were male, and $72(44.7 \%)$ were female. The male to female ratio was 0.8 . Shetty et al., and Najeeb et al. noticed more number of males getting seizures and the findings are in correlation with those of present study, though in the present study neonates were not included $[11,12]$. Similar trends were noted in studies conducted by Badwaik et al [13], Thasni et al [14], Pal et al [15], Chandraratna et al [16], Haroon et al [17].

This gender difference in prevalence rates might be attributed to some extent, to the female sex hormones i.e. estrogen and progesterone, which are known to affect the seizure threshold in females [18]. Also, in developing country like India, social stigma, need for male accompaniment for visiting hospital, lack of awareness and education might contribute to lower prevalence of epilepsy in female population [19].

In the present study, majority of the males were in the age group 5.1 to 10 years comprising of 32 patients $(36 \%)$, followed by 23 patients $(26 \%)$ in the age group 10.1 to 15 years. Female patients were majority in the age group $5.1-10$ years (46\%), followed by $26 \%$ in the age group of 1 to 5 years. In a study by Dalmia et al., seizures were predominantly observed in neonates (49\%) followed by infants and children (37\%) and adolescents $(14 \%)$. Overall the incidence of seizures decreased with increase in age [20].
From the evidences available through published literature, it is known that incidence of epilepsy follows a bimodal pattern of distribution. Initial peak is seen in the first two decades of life and the later peak is observed in advancing/ old age [21,22] In the present study, it was included only the patients who lies in the age group of 1 to 18 years.

It has been found in one study by Henry et al. that epilepsy was most commonly encountered in preschool age group. However, it was found that most commonly affected age group was 5.1 to 10 years, followed by preschool age group. It is important to analyze the age distribution in such type of epidemiological studies, as it facilitates to analyze whether there is variation in drug prescription according to different age group of patients [23].

A study by Hauser $W$ reported that between $0.5 \%$ and $1 \%$ of children and adolescents experience a seizure associated with other acute metabolic or neurologic insults; out of which maximum of them had a significant neonatal history. The incidence of epilepsy (recurrent unprovoked seizures) in children and adolescents seems relatively consistent across all populations studied, ranging from 50 to $100 / 100,000$ of which the highest incidence of epilepsy is in the twelve month of life [9].

In the present study the generalized tonic-clonic seizures were the most common seizure type among children and adolescents. Out of 161 patients $98(60.86 \%)$ patients presented with GTCS $45(27.95 \%)$, patients presented with CPS 3 $(1.86 \%)$, presented with partial seizure $6(3.72 \%)$, presented with myoclonic seizures 9 (5.59\%) presented with mixed seizures. Najeeb et al reported similar observations. In infants and children GTCS were commonest (58.2\%); next in the order noticed were simple partial (20\%), and others like complex partial (9.1\%), myoclonic $(5.6 \%)$ and absence seizures $(7.3 \%)$ were observed [12].

Similar trends were reported by Badwaik et al. [13], Pal et al. [15], Sil et al [24] in their epidemiological studies, wherein GTCS were the predominant type of epilepsy reported in these age groups. However, a South Indian study done at Coimbatore stated that most common type of epilepsy in patients aged less than 16 years was partial seizures. The authors of this study reported partial seizures in $51 \%$ of the total cases of epilepsy [25]. 
Iqbali et al. noticed GTCS to be the commonest type in this age group [26]. In adolescents GTCS were (52.4\%) followed by simple partial $(19.0 \%)$, complex partial $(9.5 \%)$ and myoclonic (19\%). Shetty KS et al reported GTCS as most common type [11]. Similarly $76.3 \%$ infants \& children and $71 \%$ adolescents had fever. The other symptoms observed in the study were: 1) Poor cry 2) Decreased movements 3) Lethargy 4) apnea/tachypnea 5) Fever/hypothermia in neonates; 6) Neck stiffness, 7) Vomiting 8) Head ache and Meningeal signs (Kernig's and Brudgiski's signs) in infants/children/adolescents [26].

However, in most of the Asian countries, there is lack of utilization of a common classification system of epilepsy, and paucity in usage of neuroimaging diagnostic modalities like EEG, CT scan, etc. This has led to generalization of types of epilepsy into generalized and partial in most of these studies [19]. Due to this, comparison of types of epilepsy in the present study with that of other studies is not always feasible.

In the present study, in generalized tonic clonic seizures sodium valproate was most commonly prescribed drug comprising of 73 patients (97\%). Carbamazepine was most commonly prescribed antiepileptic drug in complex partial seizures comprising of 36 patients ( $86 \%)$. In simple partial seizures carbamazepine was most commonly prescribed drug. In myoclonic seizures, levetiracetam was prescribed in 2 patients and valproate was prescribed in 1 patient.

The findings are in corroboration with study done by Rabindran et al [27] Among the adolescents 16 $(76 \%)$ required monotherapy with phenytoin / sodium valproate; 5 (24\%) needed dual therapy. Gosaye MT et al study concluded that at the time of discharge $92 \%$ neonates, $51 \%$ infants and children and $57 \%$ of adolescents needed no anticonvulsant; $8 \%$ of neonates, $35 \%$ of infants and children and $19 \%$ adolescents required monotherapy while $15 \%$ infants and children and $24 \%$ of adolescents needed dual therapy [28]. In the present study, sodium valproate was most commonly prescribed drug in GTCS comprising of 73 patients (97\%). Carbamazepine was most commonly prescribed antiepileptic drug in complex partial seizures comprising of 36 patients ( $86 \%)$. In simple partial seizures carbamazepine was most commonly prescribed drug. In myoclonic seizures, levetiracetam and valproate were commonly prescribed.
Overall, valproate was the commonly prescribed antiepileptic drug in the present study. Newer antiepileptics like topiramate, lamotrigine were not prescribed. This indicates the under usage of newer anti-epileptics by the physicians [15]. Interestingly, conventional antiepileptic drugs like phenytoin and phenobarbitone were not prescribed in the present study. While, choosing appropriate antiepileptic for optimal efficacy is important, it is important to evaluate whether the benefits of using these drugs outweigh their adverse effects profile [15].

Although phenytoin is commonly used in some healthcare centers, the adverse effect profile related to use of this drug has led to drastic fall in its prescription. On the other hand, its common use can be justified by good antiepileptic efficacy and lower cost of therapy [29]. In the current decade, lots of newer antiepileptic drugs have been approved by the licensing authorities, thus widening the armamentarium of antiepileptic drugs available to physician so that he/she can make appropriate choice of drug to achieve optimal control of the disease.

The ultimate aim of any antiepileptic therapy is to achieve complete symptom control, and this can be done by optimal selection and utilization of antiepileptic drugs, especially newer antiepileptic drugs, especially when conventional drugs fail to control the symptoms [30].

Limitations of the study: The results of this study were the significant but short-term. In order to study the long-term effects of spectrum of seizure disorder in children between 1-18 years of age to obtained results for a more extended population.

\section{What study adds to existing knowledge?}

The present study helps to identify the current trend in epilepsy in the region. It also helps to identify the commonly affected age group, thus it will help to formulate preventive strategies which ill majorly target the commonly affected age group. This will help to catch the disease early and help to improve the outcomes.

\section{Conclusion}

Seizures in children are a common indication for hospital admission. They can be provoked or unprovoked. Early detection of the cause of seizures helps in instituting appropriate treatment. 
Children with seizures should be on regular long term follow up and treatment and proper response to therapy should be evaluated. This knowledge will facilitate in the diagnosis, early educational intervention, and multidisciplinary therapeutic approaches.

\section{Contribution by the authors}

Dr. Himanshu Dua: Data Collection

Dr. Anjali Edbor, Dr Seher Kamal: Manuscript writing

\section{Reference}

01. Fisher R, Boas W, Blume W, Elger C, Genton P, Lee $P$, et al. Epileptic seizures, and epilepsydefinitions proposed by the International League Against Epilepsy (ILAE) and the International Bureau for Epilepsy (IBE). Epilepsia. 2005;46(4)470-472. doi: 10.1111/j.0013-9580. 2005.66104.x [Crossref][PubMed][Google Scholar]

02. Ottman R. Progress in the genetics of the partial epilepsies. Epilepsia. 2001;42(5)24-30. doi: 10.1111/j.1528-1167.2001.0s005.x [Crossref] [PubMed][Google Scholar]

03. Kramer U. Epilepsy in the first year of life- A review. J Child Neurol. 1999;14(8)485-489. doi: 10.1177\%2F088307389901400801

[Crossref]

[PubMed][Google Scholar]

04. Shawki A. Etiological and clinical presentation of epilepsy in upper Egypt MD Thesis in Neurology. Faculty of Medicine, Assiut University. 1995. [Crossref][PubMed][Google Scholar]

05. Beilmann A, Napa A, Sööt A, Talvik I, Talvik T. Prevalence of childhood epilepsy in Estonia. Epilep sia. 1999;40(7)1011-9. doi: 10.1111/j.1528-1157. 1999.tb00811.x[Crossref][PubMed][Google Scholar]

06. Serdaroglu A, Ozkan S, Aydin K, Gücüyener K, Tezcan S, Aycan S. Prevalence of epilepsy in Turkish children between the ages of 0 and 16 years. J Child Neurol. 2004;19(4)271-274. doi: 10.1177\%2F0883 07380401900406[Crossref][PubMed][Google Scholar]

07. Radhakrishnan K, Pandian J, Santhoshkumar T, Thomas SV, Deetha TD, Sarma PS, et al. Prevalence, knowledge, attitude, and practice of epilepsy in Kerala, South India. Epilepsia 2000;41(8)1027-35. doi: 10.1111/j.1528-1157.20 00.tb00289.x [Crossref][PubMed][Google Scholar]
08. International League against Epilepsy. Commission on Tropical Diseases of the International League against Epilepsy- relationship between epilepsy and tropical diseases. Epilepsia. 1994;35(1)89-93. doi: 10.1111/j.15281157.1994.tb02916.x [Crossref][PubMed][Google Scholar]

09. Hauser W. The prevalence and incidence of convulsive disorders in children. Epilepsia. 1994;35(2)S1-S6. doi: 10.1111/j.1528-1157.1994. tb05932.x [Crossref][PubMed][Google Scholar]

10. Basagana X. Power and sample size calculations for longitudinal studies estimating a main effect of a time-varying exposure. Stat Methods Med Res. 2011;20(5)471-487. doi: 10.1177\%2F096228021 0371563 [Crossref][PubMed][Google Scholar]

11. Shetty K, Ananda T, Kumar G. Etiological study of seizures among paediatric age group (1-18 years) in tertiary care medical college hospital. Int J Pediatr Res. 2017;4(4)259-263. [Crossref][PubMed] [Google Scholar]

12. Najeeb S, Qureshi A, Rehman A, Ahmad F, Shah $S$, Khan $A$, et al. Aetiolgy and types of neonatal seizures presenting at ayub teaching hospital, Abbottabad. J Ayub Med Coll. 2012;24(1)33-37. [Crossref][PubMed][Google Scholar]

13. Badwaik R, Mahajan H, Borkar A, Honrao R, Chopade SS. A Drug Utilization Study of Antiepileptic Drugs Use in a Tertiary Care Hospital of Central India. J Cont Med A Dent. 2015;3(2)33-38. doi: $10.18049 / j \mathrm{cmad} / 327$ [Crossref][PubMed] [Google Scholar]

14. Thasni K, Abdurahiman $\mathrm{P}$, Shamna S. Assessment of prescription pattern and quality of life in patients with epilepsy- A tertiary care hospital based prospective study. Int J Med Health Res. 2017;3(10)106-111. [Crossref][PubMed][Google Scholar]

15. Pal A, Prusty S, Sahu P, Sahu PK, Swain TR. Drug utilization pattern of antiepileptic drugs- a pharmaco-epidemiologic and pharmacovigilance study in a tertiary teaching hospital in India. Asian J Pharmaceut Clinic Res. 2011;4(1)96-99. [Crossref] [PubMed][Google Scholar]

16. Chandrarathna N, Praida A, Manju V, Adiga US. Drug Utilization Study in Epilepsy in a Tertiary Care Hospital. Biomed Pharmacol J. 2019;12(2)697-701. doi: 10.13005/bpj/1691 [Crossref][PubMed][Google Scholar] 
17. Haroon A, Tripathi M, Khanam R, Divya Vohora. Antiepileptic drugs prescription utilization behavior and direct costs of treatment in a national hospital of India. Ann Indian Acad Neurol. 2012;15(4)289293. doi: 10.4103/0972-2327.104338 [Crossref] [PubMed][Google Scholar]

18. Mac TL, Tran DS, Quet F, Odermatt P, Preux PM, Tan CT. Epidemiology, aetiology, and clinical management of epilepsy in Asia- a systematic review. Lancet Neurol. 2007;6(6)533-543. doi: 10.1016/S1474-4422(07)70127-8 [Crossref] [PubMed][Google Scholar]

19. George J, Jose J, Kulkarni D, Hanamantappa RR, Shalavadi CV. Evaluation of Drug Utilization and Analysis of Anti-Epileptic Drugs at Tertiary Care Teaching Hospital. Indian J Pharma Pract. 2016;9(3)189-194. doi: 10.5530/ijopp.9.3.10 [Crossref][PubMed][Google Scholar]

20. Singh RD, Suryavanshi S. A Hospital Based Study on Clinicoetiological Profile of Seizures in Children - A Kanpur (UP, India) Experience. Int J Contemp Med Res. 2016;3(10)3003-3007. [Crossref][PubMed][Google Scholar]

21. Caprio A, Hauser W. Epilepsy in the developing world. Curr Neurol Neurosci Rep. 2009;9(4)319326. [Crossref][PubMed][Google Scholar]

22. Hanssen $Y$, Dxlue D, Al Balushi $K$, et al. Drug utilization pattern of antiepileptic drugs: A pharmacoepidemiologic study in Oman. J Clinic Pharm Therapeut. 2007;27(5)357-364. doi: 10.1046/j.1365-2710.2002.00429.x [Crossref] [PubMed][Google Scholar]

23. Henry D, Sylvia A, Chidambaranathan S, Nirmala P. A prospective study of drug utilization pattern of anti-epileptic drugs and their adverse effects in a tertiary care hospital. Int J Curr Pharm Res. 2017;9(6)42-45. doi: 10.22159/ijcpr.2017v9i6.23427 [Crossref][PubMed] [Google Scholar]
24. Sil A, Das K, Das N, et al. Use of anti-epileptic drugs in a tertiary care hospital of Eastern India with emphasis on epilepsy due to neurocysticercosis. Indian J Pharmacol. 2012;44(1)106-110. doi: 10.4103/02537613.91882 [Crossref][PubMed][Google Scholar]

25. Bhajan C, Mehta P, Sunny N. A study on drug utilization pattern of antiepileptics in paediatrics at a private corporate hospital in Coimbatore, South India. World J Pharm Pharm Sci. 2017;6;542-549. [Crossref][PubMed][Google Scholar]

26. Iqbali T, Jaiswal A, Kumar A. Clinical profile of children presented with seizure in tertiary care hospital PMCH Patna, a retrospective study. Int J Med Pediatr Oncol. 2016;2(3)107-112. [Crossref] [PubMed][Google Scholar]

27. Rabindran N, Parakh H, Ramesh J, Reddy P. Phenobarbitone fot the management of neonatal seizures- A single center study. Int J Med Res Rev. 2015;3(1)1-9. doi: 10.17511/ijmrr.2015.i01.013 [Crossref][PubMed][Google Scholar]

28. Gosaye M, Woldehaimanot T, Angamo M. Poor treatment outcomes and associated factors among epileptic patients at Ambo hospital, Etiopia. Gaziantep Med J. 2015;21(1)9-16. [Crossref] [PubMed][Google Scholar]

29. Dhanaraj M, Kannan SR, Jayavelu A, Amalraj E, Dutta $M$. Cost of epilepsy treatment in a state government hospital- A preliminary study. Ann Indian Acad Neurol. 2003;6(2)7-10. [Crossref] [PubMed][Google Scholar]

30. Lim SH, Tan EK, Chen C. Pattern of anti-epileptic drug usage in a tertiary referral hospital in Singapore. Neurol J Southeast Asia. 1997;2;77-85. [Crossref][PubMed][Google Scholar] 